
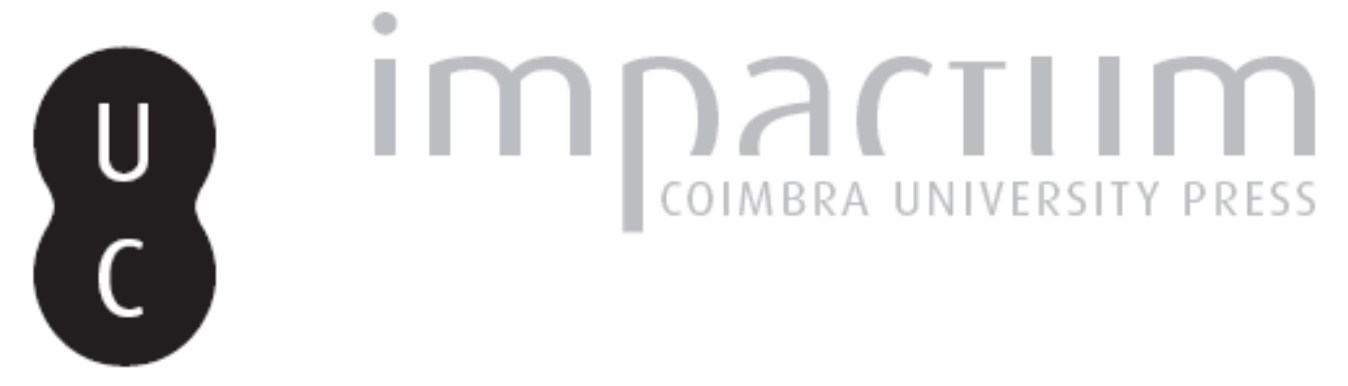

\title{
Política y ritual: reflexiones etnográficas sobre un juicio oral y público: el caso Poblete Hlaczik
}

\author{
Autor(es): $\quad$ Regueiro, Sabina
}

Publicado por: Universidade Católica de Petrópolis

URL persistente:

URI:http://hdl.handle.net/10316.2/33845

DOI:

DOI:http://dx.doi.org/10.14195/2175-0947_2-2_5

Accessed : $\quad$ 26-Apr-2023 16:16:13

A navegação consulta e descarregamento dos títulos inseridos nas Bibliotecas Digitais UC Digitalis, UC Pombalina e UC Impactum, pressupõem a aceitação plena e sem reservas dos Termos e Condições de Uso destas Bibliotecas Digitais, disponíveis em https://digitalis.uc.pt/pt-pt/termos.

Conforme exposto nos referidos Termos e Condições de Uso, o descarregamento de títulos de acesso restrito requer uma licença válida de autorização devendo o utilizador aceder ao(s) documento(s) a partir de um endereço de IP da instituição detentora da supramencionada licença.

Ao utilizador é apenas permitido o descarregamento para uso pessoal, pelo que o emprego do(s) título(s) descarregado(s) para outro fim, designadamente comercial, carece de autorização do respetivo autor ou editor da obra.

Na medida em que todas as obras da UC Digitalis se encontram protegidas pelo Código do Direito de Autor e Direitos Conexos e demais legislação aplicável, toda a cópia, parcial ou total, deste documento, nos casos em que é legalmente admitida, deverá conter ou fazer-se acompanhar por este aviso.

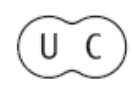



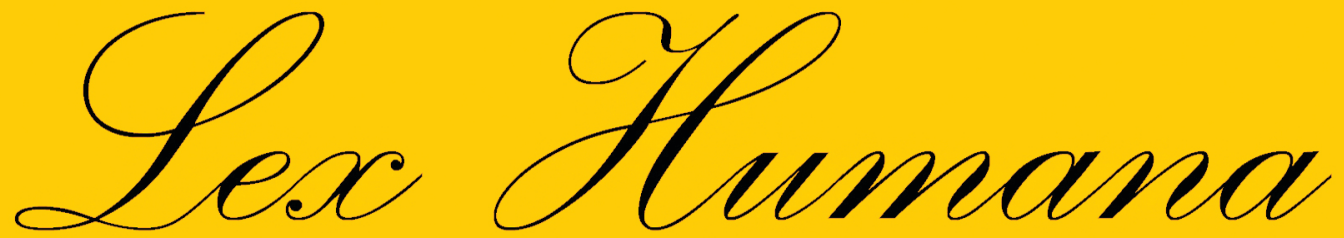

Revista do Programa de Pós-Graduação em Direito da UCP

ISSN(e) 2175-0947

Universidade Católica de Petrópolis Rua Benjamin Constant, 213 - Petrópolis - Centro CEP 25610-130

Tel: (24) 2244-4000 E-mail: lexhumana@ucp.br 


\section{POLÍTICA Y RITUAL. \\ REFLEXIONES ETNOGRÁFICAS SOBRE UN JUICIO ORAL Y PÚblico: el caso Poblete HLACZiK}

Sabina Regueiro ${ }^{1}$

Resumen: Este artículo analiza la acción política y ritual contemporánea vinculada a un juicio oral y público por la comisión de delitos de lesa humanidad, desde tres perspectivas y contextos interconectados. En primer lugar, el juicio en el tribunal puede pensarse como una "batalla ritual", constituyendo desde el punto de vista de familiares de las víctimas una "reparación". En segundo lugar, distintas organizaciones no gubernamentales realizan rituales políticos fuera del tribunal, en búsqueda de efectos concretos a partir de su acción simbólica, formando parte de la trama política que atraviesa el juicio. Por último, a nivel institucional estatal, a partir de la figura del presidente de la nación y del lugar del juicio en la política de construcción de legitimidad y consenso de su gobierno, se consideran algunas discusiones sobre la dimensión ideal del Estado. La política, el parentesco y la temporalidad ritual constituyen cuestiones abordadas transversalmente.

Palabras clave: Ritual; Justicia; Derechos humanos; Estado; Política

1 Lic. en Ciencias Antropológicas, Doctoranda Instituto de Ciencias Antropológicas, Facultad de Filosofía y Letras, UBA. Becaria Doctoral CONICET. Email: sabinaregueiro@hotmail.com. 
Abstract: This article analyzes the contemporary political and ritual action connected to an oral and public proceedings to judge crimes against humanity, from three interconnected views and contexts. Firstly, the proceedings taking place at the court may be thought as a "ritual battle", constituting a "redress" from the viewpoint of the victims' relatives. Secondly, several nongovernmental organizations perform political rituals outside the court searching for concrete effects from their symbolical action, taking part in the political plot that the proceedings undergoes. Lastly, on a state institutional level, from the figure of the president of the nation and from the place occupied by the proceedings in the policy to build legitimacy and to reach a consensus of his government, some discussions are considered regarding the ideal dimension of the Estate. Politics, kinship and ritual temporality constitute issues that are transversally addressed.

Keywords: Ritual; Justice; Human Rights; Estate; Politics

Figura 1. "Con la fuerza de la verdad/ES TIEMPO DE JUSTICIA/Juicio oral y público contra Julio Simón, el turco Julián, acusado del secuestro y desaparición de Gertrudis Hlaczik y José Poblete. Juntos conseguimos la Nulidad de las Leyes de Impunidad. ACOMPÁÑENOS el 28 de junio, 9 hs, Tribunales de Comodoro Py. Abuelas de Plaza de Mayo (logo izquierdo) CELS, Centro de Estudios Legales y Sociales (logo derecho). Afiche callejero diseñado por el CELS (Reproducción autorizada).

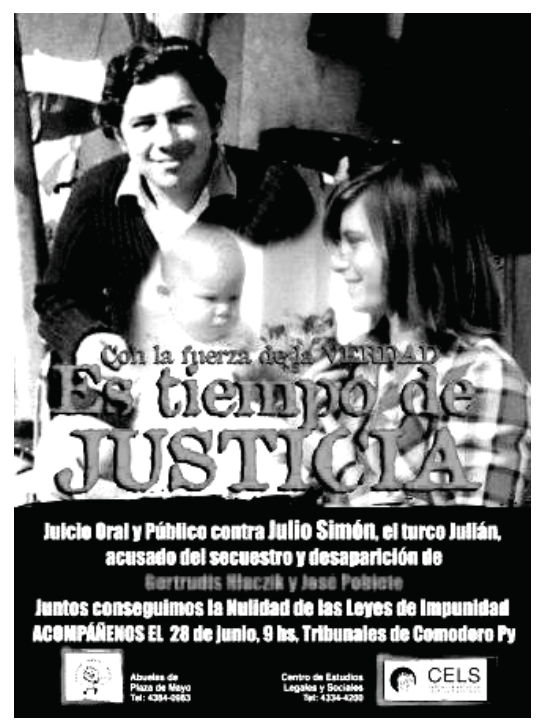


En este trabajo analizaré modalidades concretas de acción política y ritual "moderna" en el ámbito público vinculadas a un juicio oral y público por la comisión de delitos de lesa humanidad en la Ciudad Autónoma de Buenos Aires, Argentina. Retomo la idea de Marc Abélès (2006) ${ }^{2}$ de tratar lo político en el tribunal como una categoría de trabajo que produce bienes intangibles, para ver cuál es la forma particular de "fabricación" de una condena. Para ello presento una serie de relevamientos etnográficos, no ya de la Asamblea Nacional (poder legislativo) como realiza este autor, sino de un tribunal oral (poder judicial) ${ }^{3}$.

Recuperaré la propuesta de Abélès $(1988 ; 2006)^{4}$ sobre los rituales contemporáneos para la comprensión de los sentidos que los distintos sujetos en interacción otorgan a su acción política vinculada al juicio, buscando producir efectos concretos en el campo social y político, incluido el Estado, en una relación dialéctica, a través de prácticas rituales.

En este sentido, Mariza Peirano (2000) $)^{5}$ enfatiza el aspecto comunicativo de los rituales y su dimensión preformativa, partiendo de la tradición maussiana y durkheimiana que los concibe como "actos de sociedad eficaces". La autora recuerda que la temática que vincula

2

Abélès, M. Modern Political Ritual. Ethnography of an inauguration and a Pilgrimage by President Mitterrand. Current Anthropology V. 29, number 3, Chicago, p. 391-404, 1988.

3 Este artículo es una versión revisada de la monografía presentada como trabajo final en el seminario de doctorado "Antropología del Estado", dictado por el Profesor Abélès en el Centro FrancoArgentino de Altos Estudios, Universidad de Buenos Aires, entre el 23 de octubre y el 2 de noviembre de 2006. El soporte teórico de este análisis está basado en parte en las notas tomadas durante las clases del seminario, más allá de las lecturas teóricas que se referirán específicamente.

Agradezco la atenta lectura y valiosos comentarios de María Victoria Pita que contribuyeron a la realización de este artículo.

4 Abélès, M. Parliament, politics and ritual. En: Crewe/Müller (eds.). Rituals in Parliaments. Political, anthropological and historical perspectivas on Europe and the United Status. Berlin: Peter Lang, 2006.

5 Peirano, M. (org. e intro.) Análises de rituais. Série Antropologia 283, Brasília, 2000. p.

121. 
el análisis de los rituales y la eficacia social fue delineada inicialmente por Mauss en Esbozo de una teoría general de la Magia (1902) y retomado por Stanley Tambiah en Culture, Thought, and Social Action. An Antrhopological Perspective (1985) como un abordaje performativo del ritual. Presento la concepción de ritual de este último autor, cuyas distintas dimensiones serán retomadas a lo largo del trabajo.

Tambiah señala que el ritual es "un sistema culturalmente construido de comunicación simbólica. Está constituido por secuencias ordenadas y pautadas de palabras y actos, a menudo expresadas por múltiples medios, cuyo contenido y disposición se caracterizan por grados variables de formalidad (convencionalidad), esterotipia (rigidez), condensación (fusión) y redundancia (repetición). La acción ritual en sus rasgos constitutivos es performativa en tres sentidos: en el sentido austiniano, por el que decir algo es también hacer algo como acto convencional; en el sentido bastante diferente de una ejecución actuada que usa múltiples media por lo que los participantes experimentan el evento intensamente; y en el sentido de marcadores (indexical values o shifters) -tomo este concepto de Peirce que son asignados a, e inferidos por, los actores durante la ejecución" (TAMBIAH, 1985 apud María V. PITA, 2006 p.133) ${ }^{6}$. 
Como el objeto político tiene límites difusos (ABÉLÈS, 2006) por su carácter relacional, me centraré en tres ámbitos interconectados, considerando lo ritual como manifestación de lo político ${ }^{7}$ : el espacio interno del tribunal; puertas afuera, su espacio social, donde actúan las Organizaciones No Gubernamentales ${ }^{8}$ de Derechos Humanos;; y la figura de distintos funcionarios políticos, especialmente el presidente de la nación, titular del poder ejecutivo que en un estado presidencialista tiene una importante centralidad.

Desde una perspectiva antropológica, mi interpretación estará basada en las implicancias simbólicas y sociológicas de los puntos de vista de los actores que participan del juicio, ya que son constitutivos del proceso social analizado: los familiares de las víctimas y los sobrevivientes; los organismos de DDHH que organizan manifestaciones públicas durante el juicio; y el presidente de la nación, que impulsa la política de DDHH en la cual se enmarca el juicio. Consideraré la perspectiva de los dos primeros grupos en relación al juicio, específicamente sobre el papel del presidente, pensando el Estado como un conjunto de representaciones sociales, desde un enfoque durkheimiano y weberiano.

Siempre siguiendo a Abélès, dada la imbricación y autonomía relativa de lo político y lo social, retomo un enfoque de la antropología del Estado que implica no sólo analizar "la política", la práctica institucional diferenciada y elmodeloinstitucional estatal, sinotambién "lo político" en tanto concepción general, universal sobre el poder,

7

En este trabajo pretendo presentar una serie de temas vinculados entre sí en torno a la dimensión ritual de la política, dejando planteados ciertos problemas que requieren un análisis más profundo.

8 De aquí en más ONG.

9 De aquí en más DDHH. 
y trabajar a partir de un modelo de relaciones políticas de distintos grupos de actores e instituciones, donde el Estado es un principio de organización entre otros. Desde una mirada no institucionalista - fetichista de las instituciones, retomando a Pita (2006), asumo que no puede reducirse el análisis a ciertos actores (jueces y abogados), acciones (presentación de pruebas y contrapruebas) y textos (leyes y expedientes judiciales) estrictamente jurídicos, donde no se registra la perspectiva de la diversidad de agentes; las tramas políticas de relaciones de diversos sujetos que atraviesan el poder judicial; y el efecto simbólico del juicio para la política de gobierno.

En cuanto a la aproximación metodológica, en consonancia con la visión de Estado y ritual propuesta, no podemos acotarnos a un trabajo de archivo. Es por eso que presentaré observaciones etnográficas sobre el juicio, basadas fundamentalmente en mi trabajo de campo. Mi experiencia de observación participante, me permitió comenzar a analizar el problema planteado a través del estudio de las interacciones cara a cara entre los actores presentes en el territorio del tribunal, tanto dentro como fuera de la sala. En este marco, la entrevista realizada a la madre de una de las víctimas, miembro de Abuelas de Plaza de $\mathrm{Mayo}^{10}$, cuyo punto de vista en torno al juicio a partir de la trama en la que se inscribe tiene carácter protagónico, será el centro del análisis. Asimismo, el discurso de H.I.J.OS ${ }^{11}$ emitido a propósito de este acontecimiento, tendrá un lugar central.

10 De aquí en más Abuelas.

11 Hijos por la Identidad y la Justicia contra el Olvido y el Silencio. Los puntos ortográficos los separan de otro grupo de hijos de desaparecidos, "Hijos". 
El JUiCiO COMO “BATALlA RITUAL”: UNA “REPARACIÓN"

José Poblete y Gertrudis Hlaczik eran militantes de Cristianos para la Liberación, una línea colateral de Montoneros, organización política de izquierda, peronista. Son secuestrados el 28 de noviembre de 1978 junto a su hija Claudia Victoria de 8 meses de edad, siendo llevados al Centro Clandestino de Detención ${ }^{12}$ "El Olimpo" donde operaba el policía apodado "Turco Julián" quien participó de la entrega de la niña al Coronel Landa. Este militar y su mujer inscriben a la niña como hija propia meses después. En 1998 la madre de José se presenta ante la justicia ante la posibilidad de haber localizado a su nieta a partir de una denuncia recibida en Abuelas. En 2000 se inicia la causa "Landa Ceferino y otro s/supresión del estado civil de un menor" en el marco de la cual se identifica a la joven a través de un análisis genético, como Claudia Victoria Poblete. A fines de ese año, para la investigación y sanción de los responsables de los crímenes cometidos contra el matrimonio, el CELS ${ }^{13}$ se presentó ante la justicia para reclamar la inconstitucionalidad de las leyes de punto final y obediencia debida ${ }^{14}$, logrando que en 2001 la justicia federal

De aquí en más CCD.

13 Centro de Estudios Legales y Sociales (ONG) Organismo de DDHH surgido durante la última dictadura militar a partir del activismo de madres y padres de personas detenidas-desaparecidas. El trabajo del CELS en el impulso de denuncias y causas antes los tribunales, la construcción de relaciones a nivel internacional, así como la recolección y sistematización de documentación proveniente de diversas fuentes, colaboró de manera significativa, junto con el trabajo de otros organismos de derechos humanos, para la tarea que en su momento llevara adelante la Comisión Nacional por la Desaparición de Personas (CONADEP) y fuera insumo para el Juicio a la Juntas Militares.

14 La ley de Punto Final (1986) reza que "se extinguirá la acción penal respecto de toda persona por su presunta participación en cualquier grado en los delitos... que no haya sido ordenada su citación... antes de los 60 días" a partir de la fecha de promulgación de esta ley. La ley de Obediencia Debida (1987) considera que "a partir de una delimitación precisa de los alances del deber de obediencia, se tiende a fijar los limites del sistema de enjuiciamiento", por lo que "no son punibles" aquellos que revistieron cargos por debajo de ciertas jerarquías. 
las declarara nulas. Poco después tiene lugar el primer juicio oral y público contra un militar por la apropiación de una niña: Landa podía ser juzgado porque la apropiación de niños no fue incluida en dichas leyes. En 2002 Abuelas y el CELS entre otros organismos, denuncian ante la CIDH de la OEA presiones del Comandante en Jefe del Ejército y del Ministro de Defensa para que la Corte Suprema se pronuncie a favor de la constitucionalidad de las leyes. Se declaró finalmente su nulidad en 2005 en un fallo histórico, que confirmó lo que habían planteado las instancias judiciales anteriores y se declaró la invalidez e inconstitucionalidad de estas leyes por ser contrarias a normas internacionales de DDHH. Así, el 28 de junio de 2006 comenzó el primer juicio que se inicia en la ciudad de Bs. As. después de la anulación de las leyes, y el primero que llega a una sentencia histórica, a nivel nacional e internacional el 4 de agosto de 2006. El Tribunal Oral Federal $N^{\circ} 5$ sentenció a 25 años de prisión a Julio Simón (Turco Julián) por la privación ilegal de la libertad y las torturas a los Poblete y el ocultamiento de su hija.

Siguiendo a Abélès (1988) describiré someramente el tribunal, sus reglas, interacciones y atmósfera a partir de mi trabajo de campo. Para acceder al edificio, se atraviesa un detector de metales, aleatoriamente se revisa el contenido de bolsos (en mi caso sólo cuando pregunté dónde quedaba la sala) Luego con el Documento Nacional de Identidad se solicita la acreditación, se baja al subsuelo, donde existe un nuevo control policial, para acceder a la tribuna reservada a la querella, los familiares y allegados a las víctimas - frecuentemente abarrotada de gente. La del piso superior está reservada a periodistas y a la defensa, a las personas vinculadas al acusado, generalmente sólo ocupada por la prensa. Dentro de la sala, no se puede comer, beber, colocar los pies en los asientos, ni llevar computadoras o celulares. La audiencia está separada del espacio del estrado por un vidrio 
antibalas, cuyas entradas laterales están custodiadas por policías. Existen dos salidas posibles para "los de abajo", pueden volver por donde vinieron, o salir directamente a una calle interna lateral del edificio para evitar a la prensa y a los de "arriba".

La apertura de la sesión se da cuando entran los tres jueces y se sientan en el estrado, la única estructura que está por encima del nivel del piso, ante lo cual algunos miembros de la audiencia se paran y otros no ${ }^{15}$. A la izquierda, están los abogados de la querella (compuesta por las dos ONGs y familiares de las víctimas que impulsan la denuncia) con sus asesores, y el fiscal (funcionario que representa los intereses públicos) y sus ayudantes, más cerca del estrado. Del lado derecho, el acusado y sus defensores y un poco más atrás personal del juzgado. Este diseño de la sala, la organización del espacio y las reglas de interacción, no son comunes a todos los juicios orales, sino sólo a algunos especiales, altamente conflictivos políticamente (por ejemplo, la causa iniciada a partir de la voladura de la AMIA de la comunidad judía en 1994) por lo que, concretamente, están orientados a impedir el contacto entre las partes con mayor intensidad que en otros $\operatorname{casos}^{16}$.

Lo que daré en llamar la "comunidad de abajo", está conformada en su mayoría por personas vinculadas por distintos tipos de relaciones que podríamos afirmar, constituyen una especie

15

Manuel Moreira (2001:76-78) afirma que "en el campo judicial el ritual es solemne, compuesto de objetos fieles y esenciales (bandera, escudo, crucifijo), que operan como un circuito simbólico necesario para renovar distintas ceremonias, como el juramento, dentro de un espacio que modifica la óptica cotidiana al organizar la ubicación de los actores, según un orden convencional y ostentoso". Sin embargo manifiesta que es necesaria la "distinción entre las simples reglas de protocolo y los rituales judiciales". Una de las dimensiones fundamentales que determinan el carácter de ritual es la repetición, dentro de una estructura simbólica también repetida, como ya hemos mencionado al presentar la concepción de ritual de Tambiah (1985). Moreira retoma la obra de Jean Cazeneuve, Sociología del rito (1971) quien afirma que "la repetición es parte inseparable de la esencia misma del rito". Sostiene entonces que el interrogatorio es "pararitual" porque está sujeto a variaciones, en cambio el juramento es un ritual completo ya que su "omisión invalida el acto", tiene eficacia inmediata, no pueden alterarse sin afectar el resultado. "La 'eficacia' se encuentra unida a la forma y a la repetición".

16 Podríamos decir que esta organización del espacio está vinculada a una clasificación de los sujetos que van a ocuparla y un supuesto en torno al tipo de relación conflictiva que tienen. 
de comunidad moral, al menos por el hecho de compartir valores vinculados a la defensa de los DDHH: familiares, amigos, compañeros de trabajo, de cautiverio en los CCD, de militancia política en los '70, en organismos de DDHH $\mathrm{u}$ otras ONGs, funcionarios del Estado, estudiantes, etc. De acuerdo a lo que he podido observar, esta comunidad también está atravesada por conflictos externos al juicio que se expresan en su ámbito, entre familiares, funcionarios, organismos y la comisión vecinal de recuperación del CCD El Olimpo. Sin embargo en este espacio/tiempo se suspenden intencionalmente tensiones y diferencias entre sujetos e instituciones para el trabajo conjunto en el juicio (por ejemplo, entre ciertos funcionarios y la comisión vecinal de recuperación del CCD El Olimpo).

En cuanto a la atmósfera, podía observarse al comienzo, al final y en los intermedios de las sesiones, un constante intercambio sobre el juicio, saludos, abrazos, actitudes de solidaridad, lágrimas, bromas, comentarios sobre los testimonios, sobre los abogados, los jueces y el acusado ${ }^{17}$. Esto ocurre raramente durante el juicio, en voz baja, como cuando uno de los testigos mencionó en el estrado que el acusado se había presentado antes de torturarlo diciendo "Yo soy el Turco Julián", y uno de los sobrevivientes me susurró: "A mí me dijo lo mismo". Al final del juicio también hubo insultos (“ ${ } H i j o$ de puta te vas a pudrir en la cárcel!"). Fue un grito contenido que no se liberó para permitir el desarrollo del juicio, ya que la regla de silencio era controlada internamente. Sólo excepcionalmente el juez pidió orden

17 Podemos presentar algunos ejemplos para ilustrar el tipo de comentarios que realizaba la audiencia. El presidente del tribunal, quién más preguntas realizaba a los testigos, tuvo un pico de presión. Esto fue objeto de distintas interpretaciones, por ejemplo, como producto de la tensión nerviosa que le generarían los testimonios; y su voz quebrada al leer el veredicto como miedo a represalias o emoción, ya que se trataba de un fallo histórico. Se resaltaba que otro de los jueces, quien falló pidiendo una condena menor para el acusado, rara vez preguntaba y miraba constantemente a la pantalla del televisor que transmitía lo que sucedía en vez de mirar a los testigos. En relación al acusado, también se comentaban cuestiones vinculadas a la co-presencia: por ejemplo, cómo meneaba la cabeza y resoplaba sonoramente ante ciertas declaraciones. 
ante aplausos o gritos por la carga emocional de los testimonios, como lo expresa Buscarita Proa, madre de José Poblete, y miembro de Abuelas ${ }^{18}$ :

Fue una persona siniestra porque realmente al escuchar los testimonios, uno a veces sentía que quería, quería que que un agujero la tragara, porque era escuchar algo muy, muy terrible, no no, no puede ser que una persona tenga tanta maldad dentro de sí.

En otra ocasión el presidente del tribunal instó a miembros de Madres de Plaza de Mayo $^{19}$ a sacarse los pañuelos distintivos de su organización, por la prohibición de exhibir símbolos asociados a alguna de las partes, ante lo cual se retiraron. El ambiente de tensión y emoción que transmiten los sujetos no se refleja en los textos producidos (en una sentencia, en un alegato) pero forma parte integral de los sentidos de los procesos sociales.

Centrémonos ahora en ciertos "significados" que Buscarita le atribuye al juicio

El juicio al Turco Julián significó para mí y para mi familia, un poco que se hiciera justicia, no es lo que uno esperaba porque siempre uno espera más, pero el hecho de que hubiéramos podido llevar a este 
personaje tan siniestro al banquillo de los acusados durante todo un mes, en el que tuvo que poner la cara delante de todo el mundo, se enteró la clase de personaje que era, para nosotros significó sí un poco de decir bueno, es una reparación, ¿no? Una reparación a todas las humillaciones y a toda, a todos los flagelos que ha sufrido mi hijo y mi nuera en ese centro clandestino a donde este tipo prácticamente actuaba no solamente con mi familia, sino con distintas personas que estaban en ese lugar

El juicio significó “justicia” y "reparación" a nivel personal, familiar: poner públicamente en el "banquillo de los acusados", "reparar" las "humillaciones" y "flagelos" sufridos no sólo por sus familiares sino también por otras personas. El secuestro, la tortura, la apropiación de la niña en un contexto ilegal y clandestino, aunque realizado por parte del Estado durante la dictadura militar, se contrarrestaba con la justicia y condena, legal y pública, también por parte del Estado.

Al escuchar la sentencia hubo una explosión de alegría, la mayoría de los presentes se levantaron como un resorte, hubo abrazos, lágrimas: este sentido reparatorio parecía general. No reemplazaba lo irremplazable, pero simbólicamente era positivo.

En relación a su nieta, la joven "restituida", Buscarita recuerda el juicio por su sustracción ${ }^{20}$

20 Este juicio se inició por la acusación de sustracción, retención y ocultamiento de un menor de 10 años; suposición de estado civil y falsedad ideológica de documento público. La joven fue "otra" después del mismo: cambió su nombre, su filiación, su historia, su edad, su fecha de nacimiento, etc. Es el juez quien comunica este cambio de status legal y que ordena que se concrete. Este fue asumido por ella rápidamente, tal como se expresó cuando se presentó ante el juez como Claudia Victoria Poblete ¿Podría pensarse esta ceremonia judicial en particular como un rito de pasaje? Queda planteada esta pregunta que requeriría un análisis que excede este trabajo. 
A mi nieta le movió mucho, no solamente el juicio al Turco Julián, no te olvides que nosotros hicimos un juicio a los apropiadores de Claudia, el Coronel Ceferino Landa y su esposa [ . . . Claudia cuando tuvo que declarar en el juicio declaró con su verdadero nombre, declaró con el nombre de sus padres biológicos, y yo creo que eso es muy importante, que Claudia con el juicio del Turco Julián quedó más que satisfecha porque ella sabe perfectamente bien, es muy clara de que el Turco Julián tuvo mucho que ver con la muerte de sus padres y aunque ella no quiera reconocer algunas cosas con los apropiadores de ella, el Landa también tiene mucho que ver con todo esto [ . . . ] ha sido una reparación, ha sido un poco lo que ella podía haber pedido, el castigo

Así como fue importante para Buscarita el hecho de que Claudia declarara con su "nombre verdadero", es crucial que tome conciencia de la vinculación de sus apropiadores con el asesinato de sus padres. Ya durante el juicio, estaba preocupada por la información nueva que pudiera generarse en esta instancia sobre la participación de Landa en El Olimpo ${ }^{21}$ y la repercusión que esto podría tener en la perspectiva de su nieta sobre su relación con ellos.

Es por todo esto que considero que podríamos plantear esta de quien sólo se conocía el apodo, que podría tratarse de la misma persona. Luego esto no pudo ser demostrado. Más allá de que la participación de Landa en la represión se haya probado a partir de su pertenencia a la estructura de Inteligencia, el hecho de que hubiera estado en el Olimpo lo habría asociado más directamente al asesinato de los Poblete. 
confrontación pública en el ámbito del juzgado como una "lucha ritual", muy controlada, altamente formalizada, codificada por procedimientos específicos desdeelcomienzohasta elfin, estrictamente regulada y mediada por los jueces. Duby (apud Abélès, 2006) sostiene que una "batalla" es una lucha con reglas de un ritual específico: ¿podemos pensar que los actores ven al juicio como una batalla ritual en la cual se invierten los roles: el humillador es humillado? En este juicio, esta batalla trasciende lo privado, ya que implica dos grupos con cosmovisiones, intereses, ideas sociales, económicas, éticas, culturales pero sobre todo políticas, antagónicas: las víctimas y los victimarios, los militantes y los miembros del aparato represivo ${ }^{22}$, juntos de nuevo, confrontados, aunque en un espacio diferente y no ya en el campo de enfrentamiento político, militar o de cautiverio en el CCD. Esto está representando en el juicio ${ }^{23}$ y en el tribunal a partir de su organización espacial dual y anti conflicto. Parecería que los jueces al determinar la verdad se ponen de un lado o del otro, pero al imponerse la propuesta de 25 años del fiscal, ¿puede pensarse en una negociación de intereses? La "comunidad de abajo" expresaba su disgusto en relación al monto de la pena, ya que la querella pidió 50 años, a lo que hace referencia Buscarita al decir "no es lo que uno esperaba porque siempre uno espera más".

Siguiendo a Moreira (2001, p.81-83) ${ }^{24}$ resulta interesante remitir este planteo a la "tradicional discusión sobre la belicosidad

El caso simboliza más que la condena por la desaparición de esta familia, puede extenderse a otros perseguidos políticos, niños, discapacitados, pobres, judíos, extranjeros, etc., aquellas víctimas privilegiadas de esta historia.

23 Este enfrentamiento ideológico entre el acusado y los detenidos puede analizarse a partir del contenido de las declaraciones del juicio sobre lo ocurrido dentro del CCD: las evaluaciones políticas de Inteligencia, las arengas personalizadas a los detenidos liberados, el ensañamiento con judíos, extranjeros, etc. (conspiración juedomasónica) y su contrapartida en su discurso político-religioso: nosotros "somos Dios", les "perdonamos la vida" para que cuenten "lo que puede pasar a los que atentan contra esta forma de vida", occidental y cristiana. 
estructural, en cuyos extremos teóricos coexisten dos posturas que intentan vanamente dirimir si la ceremonia judicial" es un "medio ritualizado de producción de verdad o simplemente una forma simbólica de la guerra. $\mathrm{O}$ en otras palabras, si su naturaleza apunta a la transformación de la hostilidad perpetua en un simplificado mecanismo para alcanzar los objetivos bélicos sin afectar al resto del cuerpo social". El autor recuerda la hipótesis de Foucault en La verdad y las formas jurídicas al hablar del derecho germánico: el derecho es una manera reglamentada / ritual de hacer la guerra. Moreira considera que esta visión cancelaría en el derecho la idea de justicia, que el ritual jurídico reemplaza la visión punitiva de la venganza y la guerra por la búsqueda organizada de la verdad necesaria para castigar o absolver. El derecho supone la instauración de un orden, un medio de facilitar la convivencia y asegurar la paz social. La ritualización lleva al derecho como productor de verdad porque aparecen los aspectos simbólicos y ceremoniales como las fórmulas y mecanismos operacionales que deben completarse para llegar a una decisión, acusación, defensa y sentencia.

En este sentido, Antoine Garapon afirma que el proceso judicial ha sido, desde antes de la existencia del Estado, fundamentalmente un ritual, "un repertorio de gestos, palabras, fórmulas y discursos, de tiempos y lugares consagrados, destinados a dar expresión al conflicto sin poner en peligro el orden y la supervivencia del grupo" (JACOB Y MARCHAL, 1992 apud GARAPON 1999, p.25)25. Así también, manifiesta que "El primer gesto de la justicia no es intelectual ni moral, pero sí arquitectural y simbólico: delimitar un espacio sensible que mantenga a distancia la indignación moral y la cólera pública" (op. cit. pág. 19). 
Ritualización política en tribunales. ONGs: Abuelas, Madres e Hijos

Buscarita es madre de José, miembro de Abuelas y ciudadana argentina, de origen chileno ${ }^{26}$. Así, el sentido "reparatorio" que le otorga al juicio es también colectivo, para las "instituciones" y para "el pueblo argentino", dado que es un hito en el mundo político judicial. Este juicio es producto del impacto en la arena pública de luchas sociales y políticas previas de los organismos de DDHH, que trascienden el tiempo y espacio del tribunal.

[... ] significó una reparación, ¿no? un poco histórica también, porque el hecho de ser el primer juicio oral y público que se hace contra un represor de esta magnitud [ ... ] porque te podés imaginar que dentro de todo hemos conseguido lograr después de tantos años, no sólo nuestra familia sino las instituciones que han luchado durante tantos años pidiendo justicia, pidiendo castigo, yo creo que es una reparación para todos, no? [ . . . ] una reparación histórica para el pueblo argentino

Miembros de Abuelas, Madres, el CELS, H.I.J.O.S. y el MTD (Movimiento de Trabajadores Desocupados) liderado por uno de los hijos de Buscarita, organizaron un acto formal, de no más de 1 hora de duración, frente a las puertas de tribunales, montando un pequeño otorgados al juicio por Buscarita: ella le da un gran valor al acompañamiento del "pueblo argentino" "a pesar" de que su hijo era chileno. 
escenario. En este contexto de enunciación significativo, el mensaje tuvo toda clase de soportes (carteles, repetición de cantos ${ }^{27}$, aplausos, etc.). La institución más joven, H.I.J.O.S., tuvo un papel protagónico al pronunciar un discurso muy emotivo, que según Buscarita "fue muy fuerte, la verdad que fue una cosa maravillosa, los chicos estuvieron bárbaro"

[ ... ] Porque esta justicia necesita que la obliguemos a que cumpla su deber [. . . ] Por eso estamos atentos a lo que hagan los jueces Luis Di Renzi, Guillermo Gordo y Ricardo Farias. Estamos atentos porque ya no hay margen para el error [. . . . Acá estamos en el juicio a Julio Simón, alias El Turco Julián. Atentos a ver qué va a suceder [. . .] Parece que el aparato judicial no quiere avanzar. No quiere dejar de ser lo que fue. Una pata más del monstruoso aparato represor [. . .] Muchos problemas se interponen en el camino hacia la Justicia. La Cámara de Casación es un escollo muy grande. Allí es donde todo se dilata, se paraliza (H.I.J.O.S.)

El mensaje se dirige directamente hacia los tres jueces del tribunal, en una actitud de presión para que "cumplan su deber", el día de los alegatos de la querella (y la fiscalía) como un complemento de esa presentación. Se marca la relación de esta acción ritualizada con su contexto político-institucional, a partir de las referencias iremos a buscar". 
a la vinculación de la justicia con los ex represores. Esto que pasa fuera de las paredes del tribunal puede comprenderse en parte también como una relación entre las mismas fuerzas que se oponen simbólicamente en el juicio, a partir de una interpelación a la justicia para que no ocupe el lugar de los acusados. De todas formas se acercan más a una serie de "luchas informales", a una "guerra" en el sentido de Duby (apud ABÉLÈS, 2006) que a una "batalla ritual", ya que las ONGs participantes, especialmente las querellantes, a partir de una forma particular y significativa de ocupación del espacio público, cuentan con más libertad para actuar y decir lo que en el espacio de la sala del tribunal está constreñido por múltiples reglas y prohibiciones. El punto de vista de los participantes es expresado a partir de la ritualización de esta oposición, de la puesta en escena de una coreografía de la acción política, de un dispositivo político sin una institución política propiamente dicha. Esta es una expresión ritual particular del enfrentamiento mayor. Podría pensarse como la ritualización de la comunicación de disenso con el aparato judicial, de advertencia y de control cuyo objetivo parece ser influir políticamente en la sentencia, a través de la acción simbólica pública. En cuanto a la efectividad simbólica de la acción ritual, en relación a los efectos buscados, no podemos medir su eficacia a partir de los resultados: los jueces difícilmente admitan haber sido influidos por estos eventos. En cuanto a los efectos no deseados, la amenaza a la chica de H.I.J.O.S. que lee este discurso da la pauta de la eficacia simbólica de la práctica política ritualizada: "Vos y tus compañeros están jodiendo demasiado. Antes con Patti ${ }^{28}$ y ahora con el Turco Julián. Nos estamos cansando" le dijeron dos desconocidos que la abordaron en la calle, apuntándole con un arma. "No debemos estar haciendo las cosas mal, si les está

28 Policía acusado de crímenes de lesa humanidad, elegido para ocupar un cargo como diputado, el que fue finalmente impugnado. 
jodiendo" declaró la joven -que no es hija de desaparecidos, según se explicitó- en una conferencia de prensa (Página12, 10/8/06)

Cabe resaltar que dada la importancia de la estandarización (TAMBIAH, 1985; MOREIRA, 2001) para definir una acción simbólica como acción ritual - lo cual se aprecia claramente en los juicios - en relación a estos actos podríamos pensar en lo ritual como una dimensión, es decir, una acción ritualizada o una ritualización: cierta estandarización de las conductas e interacciones más que un ritual propiamente dicho. Este acto recuperó en este sentido una tradición de protesta popular común a otras manifestaciones, como el montaje de un pequeño escenario, la presencia de distintas personalidades sobre el mismo, la pronunciación de un discurso, los cantos comunes a otras marchas y eventos de este tipo, la exhibición de pancartas, carteles, banderas con las consignas sostenidas, etc. Sin embargo, el componente variable de este evento lo alejaría de una definición de ritual en sentido estricto.

Estas ONGs llevan a cabo prácticas políticas con el objetivo de lograr sanciones jurídicas sobre las violaciones de DDHH. Estas acciones son acompañadas por intentos de movilizar a la sociedad civil, como la convocatoria de Abuelas y el CELS a partir de un afiche pegado en las calles que dice "Juntos conseguimos la nulidad de las leyes de impunidad. Acompáñenos el 28 de junio, 9hs, Tribunales de Comodoro Py" (Ver figura 1) Este llamado hace referencia a un logro colectivo eminentemente político, la nulidad de las leyes. Sin embargo, su carácter político explícito varía según el caso y en distintas direcciones, y sus reivindicaciones están hechas en términos de derechos y justicia, de la expresión de un problema y no de la representatividad de un grupo o clase, de organizaciones políticas tradicionales. Nunca son neutras, todas hacen "política", más allá de sus vinculaciones con "la política", porque generan efectos simbólicos 
y materiales en los procesos sociales.

Estos "organismos" responden a la línea dominante que media entre las demás víctimas y el gobierno, pero no sólo están compuestas por familiares de las víctimas, especialmente el CELS, conformado principalmente por profesionales. Además sus objetivos son generalizables a toda la sociedad: la anulación de las leyes podría prevenir futuros crímenes. Sus vínculos y acciones exceden incluso las fronteras nacionales, están penetradas por lo transnacional, justamente a partir de su defensa de los $\mathrm{DDHH}$, vinculados al ámbito jurídico internacional ${ }^{29}$, especialmente a partir de las presentaciones judiciales, como la denuncia presentada en este caso por Abuelas y el CELS ante la CIDH a la cual me referí al principio.

Esto se expresa en la dramatización ritual, donde se presupone la solidaridad de la "comunidad imaginada" de los DDHH, de los participantes, pero además se quiere movilizar el apoyo público, la sociedad es su destinatario. En el ritual se fusiona así lo público, político y lo privado, personal, familiar ${ }^{30}$. La eficacia simbólica puede exceder el contexto inmediato, a través de su multiplicación y amplificación en los medios nacionales e internacionales, que reinterpretan y resignifican el mensaje político para los ciudadanos de manera diversa. Rompiendo con la imagen de un poder centralizado por sobre la sociedad, estas acciones ritualizadas expresan procesos políticos más profundos, ante las tensiones, los intentos de reafirmar el control de la sociedad frente al órgano político. Más allá de la formalización jurídica, del voto e incluso de la violencia, desde abajo,

Abuelas es miembro de: la Federación de Familiares de Detenidos - Desaparecidos de Latinoamérica (FEDEFAM); Defensa del Niño Internacional (DNI); Movimiento Internacional para la Unión Fraternal entre las Razas y los Pueblos (UFER); Sociedad internacional para la Prevención del Niño Maltratado y Abandonado (ISPCAN), entre otros.

30 También se une lo público y privado hacia el interior de la comunidad de los organismos, ya que varios de los padres de los hijos participantes del ritual pasaron por el Olimpo, pero no todos, así y todo la reivindicación es una. 
se participa de la vida política a partir de actos donde las palabras tienen efectos simbólicos que pueden producir transformaciones.

Otra dimensión interesante de este evento para empezar a pensar es la temporalidad

Porque la impunidad no es del pasado. La impunidad es del presente. Sobrevivimos a ella. No podemos convivir con ella. Porque construye los cimientos de una sociedad injusta. Porque está en las antípodas del mundo por el que lucharon los 30 mil desaparecidos y todos sus compañeros. A pesar del horror, principios de igualdad, solidaridad, sensibilidad social, amor por el prójimo jamás pudieron ser desaparecidos. Esto nos han dejado aquellos compañeros. Pero la impunidad nos esconde esos valores. La impunidad como pilar de este sistema cruel nos impide que como sociedad hagamos propios esos principios tan humanos que están en cada uno de nosotros. Solo que tenemos que recogerlos. Esa semilla fecunda no pudo exterminarse [ . . . ¡ 30.000 compañeros desparecidos presentes! ¡Ahora y Siempre!

En este discurso los hijos "sobrevivientes", conmemoran a sus padres biológicos o no, a sus antepasados políticos, muertos o desaparecidos, de quienes heredan una "semilla fecunda" de valores que están vigentes hoy - al igual que sus opuestos simbólicos - y deberían estarlo en el futuro: esto hace que esos "compañeros", 
"iguales" en términos de lucha política, estén presentes. Los hijos continuarán a sus padres, se "apropiarán", "recogerán" lo que les han dejado, los principios "que están" en cada uno de ellos, latentes, porque son "humanos". Así, hacen alusión a distintas temporalidades, el presente, el de los "herederos"; el pasado, el de los antepasados, y el futuro: no sólo se refieren a la militancia, la desaparición y la justicia, sino también del proceso político - institucional que lo hace posible.

¿Podríamos decir que estos actos donde se recupera la figura de los desaparecidos, en su calidad de antepasados, tienen una áurea de sacralidad?: esta dimensión de la acción ritual hace a su eficacia simbólica (a diferencia de las ceremonias, aunque ambos se desarrollen al margen de la vida cotidiana, en un tiempo especial). A modo de hipótesis, podríamos preguntarnos si este parentesco sacralizado sería entonces parte de las estrategias micropolíticas de H.I.J.O.S., Abuelas y Madres, de formas de hacer política que exceden lo institucional pero que buscan generar efectos en las instituciones, especialmente en el ámbito estatal.

Pensando en las asociaciones entre ancestros y política, Block (apud ABÉLÈS, 1988) señala que los temas de vejez, muerte y continuidad son parecidos en los rituales "modernos" y los africanos "tradicionales": la muerte simbólica del rey, el predecesor y su entrada en la comunidad de los ancestros atemporales, implica una revitalización política y simbólica, una purificación, y la continuidad, a partir de la vuelta al punto de partida simbólicamente junto a los viejos y muertos: esta sería la propuesta de H.I.J.O.S. "recoger" "la semilla fecunda" que dejaron los desaparecidos ¿Podríamos pensar que estamos ante "rituales de regeneración"? (ABÉLÈS, 1988).

Miembros de otras generaciones, como uno de los hermanos de José, participa en este acto junto al movimiento de trabajadores desocupados que lidera, el MTD “José Poblete" y al Movimiento 
Evita (kirchnerista). El MTD es de Guernica, donde la familia Poblete militaba, vivía, donde desapareció Trudi y su hija. Buscarita destaca que la gente los quería y "recuerda mucho" a su hijo, quien "dejó algo": vemos otro tipo de continuidades, territoriales y políticas.

Agrupación José Poblete [. . .] él justamente le puso el nombre del hermano, así que más en Guernica vivió Pepito, trabajó mucho también con la gente de ahí del barrio y la gente del barrio que la quería muchísimo a Trudi, a mi hijo, así que bueno, en todos los lugares donde pasó mi hijo dejó algo, no? Dejó, dejó, así que, es muy importante que, la gente lo recuerda mucho.

ESTADO, POLÍTICA Y PARTICIPACIÓN RITUAL: CONSTRUCCIÓN DE LEGITIMIDAD Y CONSENSO

Eduardo Luis Duhalde ${ }^{31}$, él nos acompañó mucho con los medios, y Ibarra ${ }^{32}$ que estuvo con nosotros, también nos acompañó y el hijo de Estela, Remo Carlotto yo creo que tuvo un apoyo muy grande de todos los diputados, porque estuvieron muchos

31

Secretario de DDHH de la Nación, Ministerio de Justicia y DDHH. Militante peronista durante los años '70, vinculado al Peronismo de Base y luego al Partido Revolucionario de los Obreros Argentinos.

32 Ex fiscal en el Juicio a las Juntas militares en 1985 y en una causa abierta por el Ministerio Público Fiscal para la investigación de apropiación de niños durante la última dictadura. Ex Jefe de Gobierno porteño (destituido por el incendio del boliche bailable Cromagnon donde murieron 194 personas) Candidato a legislador kirchnerista por la ciudad en ese momento (actualmente diputado) 
diputados que casi no le sé el nombre, les agradezco mucho.

Buscaritamencionaalgunos delospersonajes delcampo político que estuvieron vinculados al juicio. La presencia en ceremonias de inauguración y conmemoración en general son aspectos importantes de la representación política, porque hacen a la construcción de legitimidad, es decir de poder. Menciona a Remo Carlotto, diputado kirchnerista y ex secretario de DDHH de la provincia de Bs. As., hijo de Estela de Carlotto, presidenta de Abuelas; hermano de Claudia Carlotto, directora de la CONADI (Comisión Nacional por el Derecho a la Identidad), dependiente de Duhalde. Esto nos da la pauta de la integración de la ONG con el Estado (poder ejecutivo y legislativo). Además vemos una nueva faceta de la relación parentesco (entre sí y con las víctimas) y política, a partir del factor genealógico de construcción de redes políticas (POURCHER, 1985) 33 , como fuente de legitimidad, a partir de la mirada sobre actores concretos. Si bien la vinculación de Abuelas con el Estado fue una constante, la relación con este gobierno se construyó sobre una identificación de intereses, dado que los DDHH constituyen una de las bases de su programa político $^{34}$. Buscarita sostiene que el juicio fue posible gracias al presidente Néstor Kirchner

Pourcher, Y. Parenté et représentation politique en Lozère. Terrain 4, Paris, Éditions de la Maison des sciences de l'homme, p. 27-41. 1985.

34 Cristina Fernández de Kirchner, senadora, primera dama y posible candidata a presidente en ese momento (actualmente presidenta), afirmó que "la República Argentina, a partir de la administración del presidente Néstor Kirchner (actualmente fallecido), ha hecho de los DDHH uno de los pilares básicos de su política" (TELAM, 6/2/07). La inclusión de los DDHH en la plataforma electoral de Raúl Alfonsín fue crucial para su triunfo en 1983 (auque durante su gobierno se crearon las "leyes de impunidad"). 
Fue posible en este momento porque no te olvides que esto viene desde larga data, los organismos vienen peleando por esto desde hace muchos años, pero yo pienso que aunque haya gente que no reconozca esto tiene mucho que ver con el presidente Kirchner y esto no es ninguna propaganda al presidente, simplemente a mí me parece que esto hubiera sido mucho más difícil sin el presidente este, porque a nosotros nos ha comprobado que ha luchado mucho por los derechos humanos, ha tenido la suficiente valentía como para desalojar la Escuela de Mecánica de la Armada, como para devolvernos parte de los centros clandestinos

El espacio del juicio es propicio para realizar denuncias y demandas, apelando a la "voluntad política" de generar cambios institucionales, como hace H.I.J.O.S. sobre la cámara de Casación

Allí es donde se encuentran jueces cómplices de los militares, al punto que el Dr. Bisordi, por ejemplo, califica de 'delincuentes terroristas' a las víctimas

[. . .] los fiscales: Juan Martín Romero Victorica, Raúl Pleé, Ricardo Weschler y Pedro Narváez, resultan un obstáculo esencial. Esto hay que solucionarlo. Una voluntad política podría revertir esta situación. La Cámara de Casación no debería existir ${ }^{35}$ estado de 1976 Kirchner cuestionó las "demoras" para resolver causas pendientes contra los militares. Ministros del gobierno nacional habían pedido a Bisordi que "le haga un favor a la patria y renuncie" al 
La referencia de Buscarita a la "propaganda", tiene su razón de ser. Kirchner gozaba en ese momento de un amplio consenso, especialmente a partir de la centralidad que adquirió el discurso de los DDHH impulsado desde su asunción ${ }^{36}$, más allá de los familiares de las víctimas, mientras que había asumido en el 2004 con sólo el $20 \%$ del apoyo del electorado. Esto se vio en el triunfo del Frente para la Victoria en las elecciones legislativas del 2005 y en la intención de voto para las elecciones de gobernadores y presidente del 2006.

Las formas representativas del poder válidas para nuestra sociedad, su concepción implícita del poder, incluye una expectativa de justicia para los crímenes de lesa humanidad. Eventos y acciones concretas como el pago de la deuda externa, la represión actual a los trabajadores (caso Fuentealba), los desaparecidos por motivos políticos (casos López y Gerez), no socavaron su consenso mayoritario $^{37}$ fortalecido a partir del trabajo simbólico de sus discursos donde el presidente apela a la creencia en determinados

cargo (www.perfil.com, 17/4/07).

36 En una encuesta sobre los crímenes de la dictadura militar, una mayoría está de acuerdo con las críticas de Kirchner a la lentitud de los procesos y también con que promueva los juicios. El 70\% afirma que los juicios son algo positivo para el país y no admite la relevancia de la distinción entre los que ordenaron la represión y los que cometieron los crímenes: todos son igualmente culpables (contrario a la ley de obediencia). 2/3 de los encuestados aprueban la política de revisión del pasado que impulsa el Gobierno y un 55\% concuerda con el énfasis que le da al tema el Presidente en sus discursos y acciones. Es absoluta la mayoría que considera importante mantener el tema en la agenda y rechaza una amnistía a los procesados. En cuanto al enfrentamiento con la Casación, el 50\% ve el discurso de Kirchner del 24/3 como ajustado a la verdad. Sin embargo $2 / 3$ consideran justo que se investigue también a los militantes de organizaciones perseguidas, lo cual requeriría otro análisis (Página 12, 1/4/07).

37 Son interesantes en este sentido dos titulares de la irónica revista Barcelona que sugieren que los DDHH justifican otras acciones: "El presidente y su compromiso con los DDHH. Kirchner: 'Es fascista hablar de inflación mientras Julio López está desaparecido" (2/3/07) "La política de DDHH, más prioridad que nunca. Memoria. El gobierno promete que si reprime en Santa Cruz inmediatamente construirá un museo para recordar las víctimas" (30/3/07). 
valores: los naturalizados $\mathrm{DDHH}^{38}$. Buscarita considera que hay ciertas características de la gestión de Kirchner que deben ser contextualizadas, ya que son producto de la dictadura y gobiernos anteriores

El presidente Kirchner me parece que puede tener sus falencias como cualquiera, puede haber cosas que no están bien, o que no se están haciendo como corresponde pero no olvidemos que estamos en un país muy grande, quedó totalmente desvastado después del golpe de Estado, y no hubo ningún presidente que lo levantara totalmente (Buscarita)

En este sentido, podríamos preguntarnos si la batalla ritual del juicio y sus rituales políticos asociados, serían parte de una estrategia mayor de construcción de legitimidad a nivel del gobierno nacional. Su importancia simbólica influiría en la construcción de la imagen de los representantes que participan, generando un efecto simbólico de poder, en su legitimidad. Esta función política del juicio sería posible por su carácter público y su transmisión en los medios. Esta hipótesis se basa en el supuesto de que la búsqueda de consenso es una de las bases de la representación política, y si la política de DDHH está en el centro de las políticas de Estado, definiendo la identidad de este gobierno, podríamos decir que el juicio estaría jugando un papel

38 Una de las voces críticas de la política de DDHH de Kirchner es la de Adriana Calvo (actualmente fallecida), compañera de Julio López, quien recuerda que el fiscal que representó al Estado en el juicio contra el Turco Julián está denunciado por presenciar torturas durante la dictadura y que el sumario que se le abrió a partir de las denuncias de la Asociación de Ex Detenidos-Desaparecidos, a la cual ella pertenece, lleva casi dos años de trámite. Afirma que "lo que sí está consolidado es el discurso de que existe voluntad política de juzgar a los represores" pero que "del dicho al hecho hay mucho trecho" y que espera "el día que en nuestro país haya justicia, en vez de parecer que la hay". 
como fuente de legitimidad.

La política de DDHH del gobierno se vincula directamente a la construcción de una imagen pública del presidente como militante en los '70, dentro del peronismo de izquierda, una generación política particular ${ }^{39}$ : esto constituiría una fuente de legitimidad para parte de la población. Así también, hay varios ex militantes en cargos clave en el gobierno. Pero, diversos actores del campo político intentan exaltarlo y otros demonizarlo llamándolo "montonero" 40 . Los políticos tienen poder de evocación, en ciertos rituales intentan expresar en forma material su identificación continuada con su comunidad, conmemorando eventos que significativamente la marcaron, fundacionales, hitos históricos, períodos de conflicto intenso, como la dictadura, que continúan capturando la imaginación colectiva, que aparecen como la encarnación de una herencia común, y manipulando símbolos que orientan su acción de gobierno (ABÉLÈS, 2006).

Esto introduce otra dimensión de análisis a la discusión, que sólo quiero dejar planteada. Según la tradición maussiana, la división entre política, religión y sociedad es artificial, no corresponde a las prácticas sociales reales ${ }^{41}$. En este caso, el presidente parecería

Kirchner desde el peronismo participó de la Federación Universitaria de la Revolución Nacional de La Plata, la Federación de Agrupaciones Eva Perón y las Fuerzas Armadas Revolucionarias. Un grupo de las FURN se incorpora a Montoneros pero Kirchner no. Era un militante periférico, no participó en la resistencia (www.hlediario.cjb.net).

40

Kirchner construye su vida de militante, declarando: "Si hubiese sido montonero lo habría dicho. Lo que en cambio es cierto es que participé en la tendencia (revolucionaria). Y estoy orgulloso de mi pasado" (Clarín, 6/5/03) También se presentó en las Naciones Unidas como un "hijo de las Madres de Plaza de Mayo", como parte de esa generación del '70 (www.hlediario.cjb.net) Sus enemigos políticos lo califican despectivamente de montonero, diciendo que coparon el Estado argentino "habiendo hecho muy bien sus deberes gramscianos". Lo acusan de dedicarse "en vez de a gobernar para La Nación, a participar en actos junto a terroristas"; de haber dicho en la ESMA: "venimos a continuar la gesta de los Montoneros", lo cual no fue probado. Y además, de querer imponer la memoria de los años '70 en las nuevas generaciones (www.ilhn.com, 20/4/04)

41 Lett (en Abélès, 1988) sostiene que el ritual presidencial que analiza Abélès es simbólico pero no religioso, ya que lo religioso no es lo mismo que lo sobrenatural, lo no empírico. Los símbolos de identificación grupal, nacional, de herencia cultural, manipulados por el presidente son seculares, no dependen de lo sobrenatural. En su forma y función son idénticos a los religiosos, pero no lo son. 
querer encarnar lo sagrado, los mártires, sean héroes o víctimas inocentes, cuyo proyecto político es recuperado y resignificado. En la batalla ritual del juicio él estaría del lado de las víctimas (era peronista como José Poblete) y de la justicia como parte del Estado; en los rituales políticos de H.I.J.O.S., él sería parte de la generación de los "compañeros desaparecidos" que son reivindicados; como presidente, parecería basar su política de Estado justamente en la justicia para esos crímenes, respondiendo a las demandas sociales y construyendo consenso a su vez.

Palabras finales

Retomando el último punto desarrollado, el Estado lleva a cabo el juicio a través de su poder judicial, lo cual es posible a su vez porque el legislativo sentó las condiciones con la anulación de las "leyes de impunidad", y el ejecutivo dio su visto bueno a los legisladores ${ }^{42}$. Sin embargo, desde una perspectiva weberiana el Estado no puede ser considerado desde una mirada jurídica como algo fijo: hay que pensar en su dimensión ideal, en las representaciones mentales de lo político, colectivas y heterogéneas, que orientan las acciones, y son a su vez producto de procesos sociales. Así, reflexioné sobre la dimensión ritual de las prácticas políticas vinculadas a este juicio para analizar el punto de vista de los sujetos vinculados a tres

\footnotetext{
Abélès afirma que no existe una secularización total de la política moderna, y plantea un debate en torno a la dimensión religiosa de estos rituales, que responde a la creencia en dios, en la nación y que eso es expresión de religión: así, considera a las ceremonias de conmemoración de caídos en la guerra, como "cultos seculares", sin dios ni cura: ¿Sería éste uno de estos casos?

42 En 2003 Kirchner dijo públicamente que si el congreso anulaba las leyes estaría de acuerdo siempre que no generara problemas legales, lo que fue entendido como una luz verde para los legisladores (www.gerechtigkeit-heilt.de, 16/10/05)
} 
contextos interrelacionados: el espacio del tribunal, el espacio social de las ONGs, y la figura del presidente como encarnación del Estado. La política de DDHH del gobierno de Kirchner no es algo ajeno a la sociedad, impuesto desde arriba, y por eso mismo juega un papel en la construcción de legitimidad del gobierno desde abajo, a partir del establecimiento de relaciones sociales y de poder entre personas con voluntad de dominación y de obediencia, en un intercambio de bienes simbólicos, como esta condena. El Estado responde a la sociedad y provoca efectos sobre ella, transformándose ${ }^{43}$ : incorpora las demandas de justicia de los organismos de DDHH, las hace propias y las traduce en políticas de DDHH; a su vez es recreado y construido por la aplicación de esas políticas a través del juicio; y los organismos son transformados y sus actos resignificados en el proceso ${ }^{44}$.

Así, se construye legitimidad a través de distintos actos rituales del presidente y de los "organismos", como H.I.J.O.S., donde se comunica, se transmiten mensajes en una y otra dirección, cuya eficacia simbólica produce transformaciones concretas a través de distintas mediaciones. En este proceso, el juicio parecería tanto un espacio de representación de la confrontación de grupos políticos en la arena política pública, como de solidaridad, a partir de su efecto de "reparación" social, donde el gobierno parece estar del lado de las víctimas. La condena está en el contexto de un intercambio que se combina con otros mecanismos de construcción de consenso: la identidad construida del presidente como militante se parecería enlazarse con lo sagrado, los desaparecidos, como una "vuelta a los orígenes" (ABÉLÈS, 1988), así como un rey europeo es legitimado en parte por dios y un jefe indígena por los ancestros de su comunidad. alienación en el Estado, está fundamentado en la lucha de clases, pero no es su simple reflejo.

44 Críticos de este gobierno denominan esta transformación como una "cooptación" de los organismos de DDHH. 
Referências Bibliográficas

ABÉLÈS, M. Modern Political Ritual. Ethnography of an inauguration and a Pilgrimage by President Mitterrand. Current Anthropology V. 29, number 3, Chicago, p. 391-404, 1988.

Parliament, politics and ritual. En: Crewe/Müller (eds.). Rituals in Parliaments. Political, anthropological and historical perspectivas on Europe and the United Status. Berlin: Peter Lang, 2006.

GARAPON, A. Bem julgar. Ensaio sobre o ritual judiciário. Rio de Janeiro: Instituto Piaget, 1999.

MOREIRA, M. Antropología del control social. Bs. As.: Editorial Antropofagia, 2001.

PITA, M. Formas de morir y formas de vivir : los familiares de víctimas de la violencia policial. 2006. 229 h. Tesis (Doctorado en Antropología) Facultad de Filosofía y Letras, UBA, Buenos Aires. 2006.

PEIRANO, M. (org. e intro.) Análises de rituais. Série Antropologia 283, Brasília, 2000. p. 121.

POURCHER, Y. Parenté et représentation politique en Lozère. Terrain 4, Paris, Éditions de la Maison des sciences de l'homme, p. 27-41. 1985. 